\title{
28. PALYNOLOGICAL STUDY OF SEDIMENTS IN HOLES 439 AND 438A
}

\author{
Seiji Sato, Department of Geology and Mineralogy, Hokkaido University, Sapporo, Japan
}

\section{INTRODUCTION}

The main purpose of the present study is to obtain a complete sequence of pollen flora through the Cenozoic in the Pacific offshore area off northeastern Japan. Recently, the Pacific coast area of northern Japan, especially Hokkaido, has been a focus for oil exploration, including deep drilling. Drillings recovered abundant fossil pollen and spores in almost all land formations. However, in the offshore area covered in this study, there is only scarce stratigraphic data and no palynological data at all. Therefore, the present results are of great importance in correlating the structure and geologic history of the deep sea area off northern Japan with that of similar areas.

\section{METHODS}

Since the samples used in the present study range in geologic age from the Cretaceous(?) to the Pleistocene, our methods varied accordingly. The materials were prepared by the following procedures.

Hole 439, Cores 5 through 9. Samples were (1) boiled in a 10 per cent $\mathrm{KOH}$ solution for $2 \mathrm{hr}$., then washed by water; (2) soaked in hydrofluoric acid for 2 to $18 \mathrm{hr}$., then washed by water; (3) heated in a mixture of nitric acid, hydrochloric acid, and water (1:1:1 in volume) at $60^{\circ} \mathrm{C}$ for $5 \mathrm{~min}$., then washed by water (procedures [2] and [3] were repeated 3 or 4 times); and (4) slides were prepared.

Hole 439, Cores 10 through 39. Samples were (1) soaked in Schultz solution for 1 to $15 \mathrm{hr}$. (1 hr. for Cores 10 and $11,6 \mathrm{hr}$. for Cores $12-28,15 \mathrm{hr}$. for Cores $30-39$ ), then washed by water; (2) heated in a 10 per cent $\mathrm{KOH}$ solution $\left(60^{\circ}-70^{\circ} \mathrm{C}\right)$ for 30 to $50 \mathrm{~min}$., then washed by water; (3) soaked in hydrofluoric acid for 2 to $18 \mathrm{hr}$., then washed by water; (4) heated in a mixture of nitric acid, hydrochloric acid, and water $(1: 1: 1$ in volume) at $60^{\circ} \mathrm{C}$ for $5 \mathrm{~min}$., then washed by water (procedures [3] and [4] were repeated 3 or 4 times); and (5) slides were prepared.

Hole 438A, Cores 1 through 85 . Samples were (1) boiled in a 10 per cent $\mathrm{KOH}$ solution for 40 to $120 \mathrm{~min}$. (40 min. for Cores 1-3, $60 \mathrm{~min}$. for Cores 4-12, 100 min. for Cores $13-75,120 \mathrm{~min}$. for Cores 76-85), then washed by water; (2) treated with hydrofluoric acid and the same mixture as for Hole 439; and (3) slides were prepared.

\section{RESULTS FOR HOLE 439}

The results of the pollen analysis of the sediments in this hole are shown in the polen diagram (Figure 1). No pollen or spores were found below 1097 meters (Cores 32-39). From these results I infer the following.

1) On the geologic age of the bottom part of the hole: Samples 439-38-1 and 439-39-1 are considered Cretaceous, based on their foraminiferal fossils; however, I regard them as Tertiary, based on the results of the pollen analysis. Although Samples 439-39-1 (1154 $\mathrm{m})$ and 439-38-1 (1149 $\mathrm{m}$ ) were expected because of their lithology ${ }^{1}$ to be rich in fossil pollen and spores, few pollen grains were found: there was one grain of Betula in the former and one grain of Alnus, two of Betula, and one of Taxodiaceae in the latter. Alnus and Betula pollen are commonly found in Tertiary sediments but are rare or absent in Cretaceous sediments, except in the uppermost part. Accordingly, the occurrence of these pollen may indicate the samples to be from the Tertiary, though the pollen grains may be Upper Cretaceous. Judging from the reaction to the $\mathrm{KOH}$ solution during maceration treatment, the samples seem to contain much humic organic matter, which may have originated mainly from plant remains. Generally, there are many fossil pollen and spores and fragments of various other plant tissues in slides made from these rocks. However, as I noted earlier only a few pollen and spores were found among many organic particles whose black or dark brown may have indicated resinous or waxy materials. Perhaps the samples were clastic materials that had undergone much weathering and leaching.

2) The hole is in close proximity to the land space. The most noteworthy feature in the pollen diagram is the occurrence of characteristic pollen and spores derived from Cretaceous rocks (DSP). They occur with high frequency in the section between 1050 and 1005 meters. Generally, because it is impossible to distinguish between Cretaceous and Tertiary spores and Pinaceae pollen, they are shown in a lump in the diagram. It is also known from pollen analysis of Cretaceous rocks that a considerable quantity of spores and Pinaceae occur with the aforementioned characteristic pollen and spores (DSP). Consequently, it is presumed that the majority of fossil pollen and spores found in the section are derived from Cretaceous rocks. The reworked fossil pollen and spores suddenly disappear at the horizon of 1000 meters. This horizon corresponds to the boundary between the Paleogene and Neogene. I consider this occurrence of DSP to indicate that the source of the sediments were essentially Cretaceous rocks and that this source was near the present hole. That is, a land area

\footnotetext{
${ }^{1}$ In general, normal argillaceous rocks are rich in both pollen and spores.
} 
GROUP A

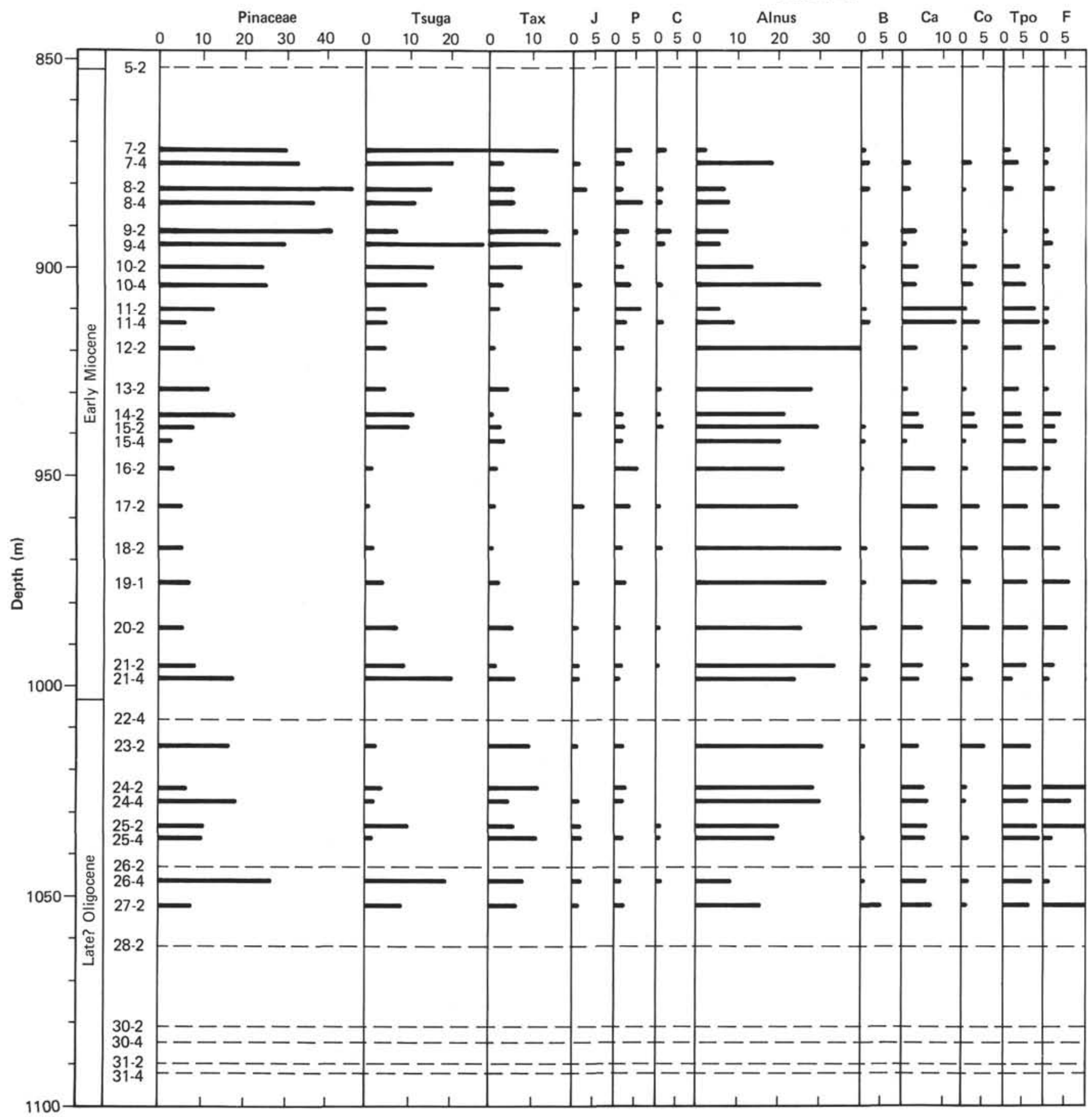

Figure 1. Pollen diagram of Hole 439 sediments. The age assignment is based on diatoms, radiolarians, nannofossils, and foraminifers. Group A pollen types are shown as relative per cent of the total pollen assemblage (counts of 150200 pollen grains). Group B (microplanktons, spores, and Sporomorph A) are shown as percentage abundance relative to pollen; thus percentage can exceed 100. Key: Tax: Taxodiaceae. J: Juglans. P: Pterocarya. C: Carya. B: Betula. Ca: Carpinus. Co: Corylus. Tpo: Triporate pollen, genus indeterminable. F: Fagus. Q: Quercus. Tcl: Tricolpate pollen, genus indeterminable. U\& Z: Ulmus and Zelkova. L: Liquidambar. R: Rhus. I: Ilex. T: Tilia. Microplanktons: mainly dinoflagellata and acritarchs. Ts: Trilete spores. Ms: Monolete spores. DSP: Spores and pollens clearly judged to derive from Cretaceous rocks, based on their characteristic shapes. Sporomorph A: Spherical, less than $10 \mu \mathrm{m}$ in diameter, surface smooth, biological affinity unknown, not found in terrestrial sediments. ---- Horizon containing very few or no pollen and spores. 

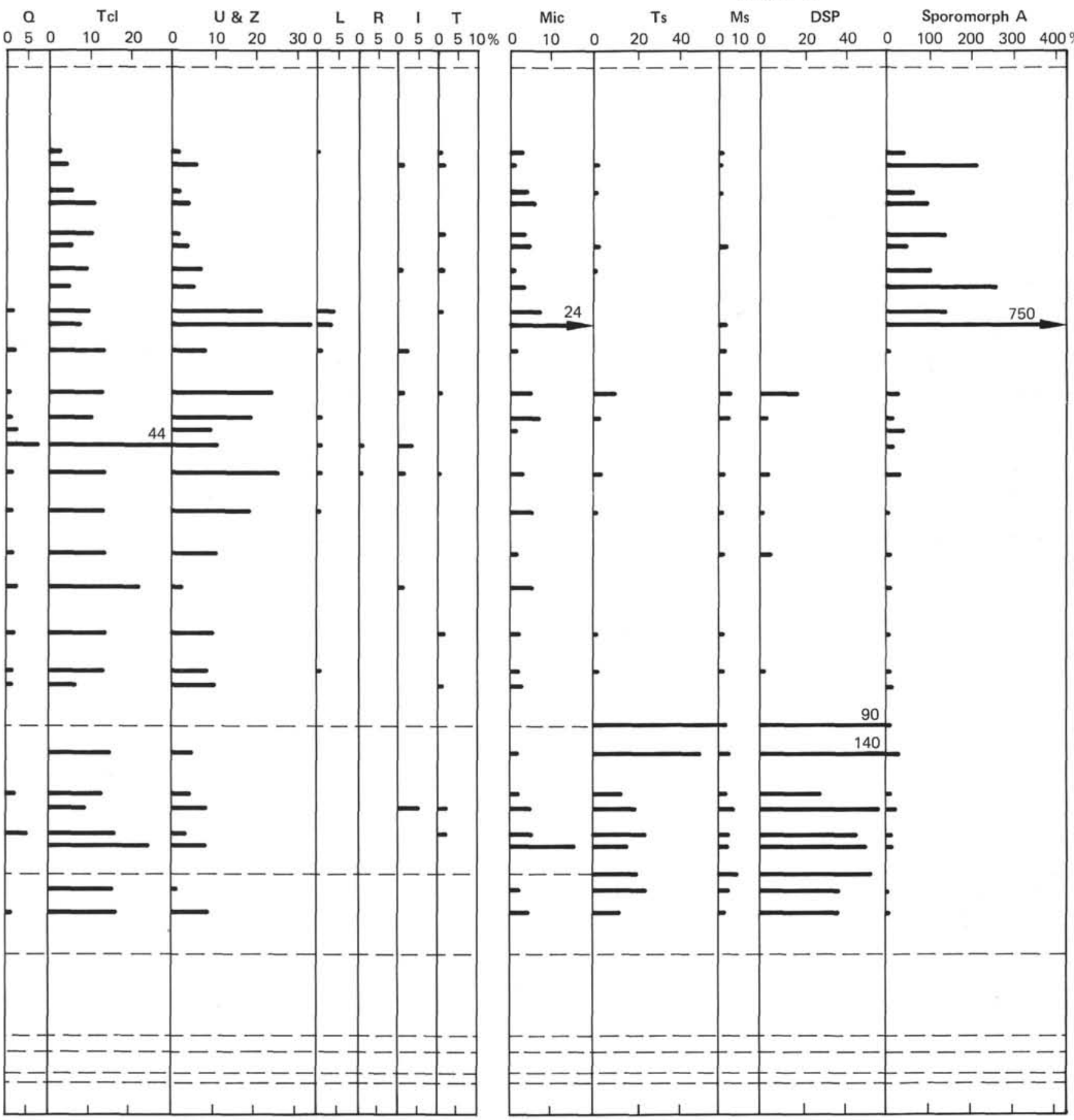

Figure 1. (Continued).

composed of the Cretaceous rocks existed in the sea area off the Sanriku district during the time represented by the sediments in the section between 1050 and 1005 meters, and that land was surely ${ }^{2}$ covered by sea when the Neogene sediments in the present hole began to accumulate.

${ }^{2}$ The Neogene may overlie the Paleogene with unconformity in the present hole; that is, some sediments may be missing between Core 22-4 and Core 23-4. Yet none of the shipboard data makes reference to a missing section.
3) There is not enough palynostratigraphical data from Northeast Japan available for comparison with the present study. However, according to the study of macrofossil plants, the earliest Neogene deposits are characterized by Aniai-type flora, indicating a cool, temperate climatic condition (Tanai, 1961). It is also reported by Tanai and Huzioka (1967) that the climate during the Paleogene had lower temperatures toward the end of the Paleogene or at the beginning of the Neogene. It is further ascertained by the palynological study of Tertiary formations in Hokkaido that a cool or 
cool-temperate climate prevailed during the late Oligocene and earliest Miocene. Pollen assemblages in which Pinaceae and Tsuga (whose presence we can regard as indicating cool, temperate climatic conditions) predominate frequently occur in the late Oligocene and earliest Miocene (Sato, 1963, 1970, 1972). However, there is no pollen assemblage indicating distinctly cool climate in the lower Neogene or upper Paleogene in Hole 439. Pollen of both the Pinaceae and Tsuga shows a tendency to increase in abundance toward the lower Neogene from the horizon of 950 meters. The pollen assemblage of Sample 439-21-4 may be part of a cool climate assemblage in the earliest Neogene. At any rate, I consider the sediments of the latest Paleogene and the earliest Neogene to be missing in the present hole.

4) The section between Samples 439-12-2 and 439-21-2 is characterized by a pollen assemblage indicating a rather warm-temperate climate. Comparing the Neogene pollen floral sequence from the Hole 439 with that from Hole $438 \mathrm{~A}$, the former indicates the warmest climate of all sections of the Neogene. Considering the Neogene floral sequence in northern Japan, Hole 439 correlates with the Daijima and Nishikurosawa Formations in northeast Honshu, which were deposited during the warmest climate in the Neogene.

5) According to diatom data, a hiatus exists at the horizon between Samples 439-11-4 (911 m) and 439-12-2 $(918 \mathrm{~m})$. Microplanktons and Sporomorph A, which are considered to indicate a marine condition, occur abundantly, from Sample 439-11-4 up. This may imply some change in depositional environment and support the aforenoted inference from diatom data.

\section{RESULTS FOR HOLE 438A}

1) The boundary between the Tertiary and Quaternary. I expected the boundary between the Tertiary and Quaternary to be clearly marked by an abrupt increase in cool elements of pollen in the Quaternary. However, as the diagram shows (Figure 2), the expected change of pollen flora did not occur at this boundary (which had been based on such fossils as radiolarians, diatoms, nannofossils, and foraminifers). The pollen analysis indicates the boundary to be between Samples 438A-5-2 and 438A-6-2, judging from the higher frequency of Pinaceae in Samples 438A-4-2 and 438A-5-2.

2) Except for the aforenoted change, there is no striking alteration in composition of pollen flora in Hole 438A. On the whole, the pollen flora may represent a cool-temperate climate. Only Taxodiaceae pollen tends to increase in frequency in the section from 600 to 100 meters. Microplanktons and Sporomorph A, which indicate a marine element, are most abundant from 820 to 600 meters (middle Miocene).

\section{ACKNOWLEDGMENTS}

I thank Professors Noriyuki Nasu, Ocean Research Institute, University of Tokyo, and Hakuyu Okada, Shizuoka University, for providing the opportunity to do the present research. My appreciation is also due to Professor Toshimasa Tanai, Hokkaido University, for his advice and discussion of the study. Professors Noriyuki Nasu and Hideo Kagami reviewed the manuscript.

\section{REFERENCES}

Sato, S., 1963. Palynological study on Miocene sediments of Hokkaido, Japan. J. Fac. Sci. Hokkaido Univ., Ser. 4, 12 (No. 1), 1-110. ,1970. On the stratigraphy and correlation of Miocene sediments in Central Hokkaido-with special reference to palynology of marine sediments. J. Geol. Soc. Jpn., 76 (No. 6), 283-301. (in Japanese) 1972. Palynological considerations of Tertiary marine sediments of Hokkaido, compared with animal faunas. J. Fac. Sc. Hokkaido Univ., Ser. 4, 15 (Nos. 1,2), 217-272.

Tanai, T., 1961. Neogene floral change in Japan. J. Fac. Sci. Hokkaido Univ., Ser. 4, 11 (No. 2), 119-398.

Tanai, T., and Huzioka, K., 1976. Climatic implications of Tertiary floras in Japan. In Hatai, K. (Ed.), Tertiary Correlation and Climatic Change in the Pacific: Tokyo (11th Pacific Science Congress. Symposium No. 25), pp. 89-94. 


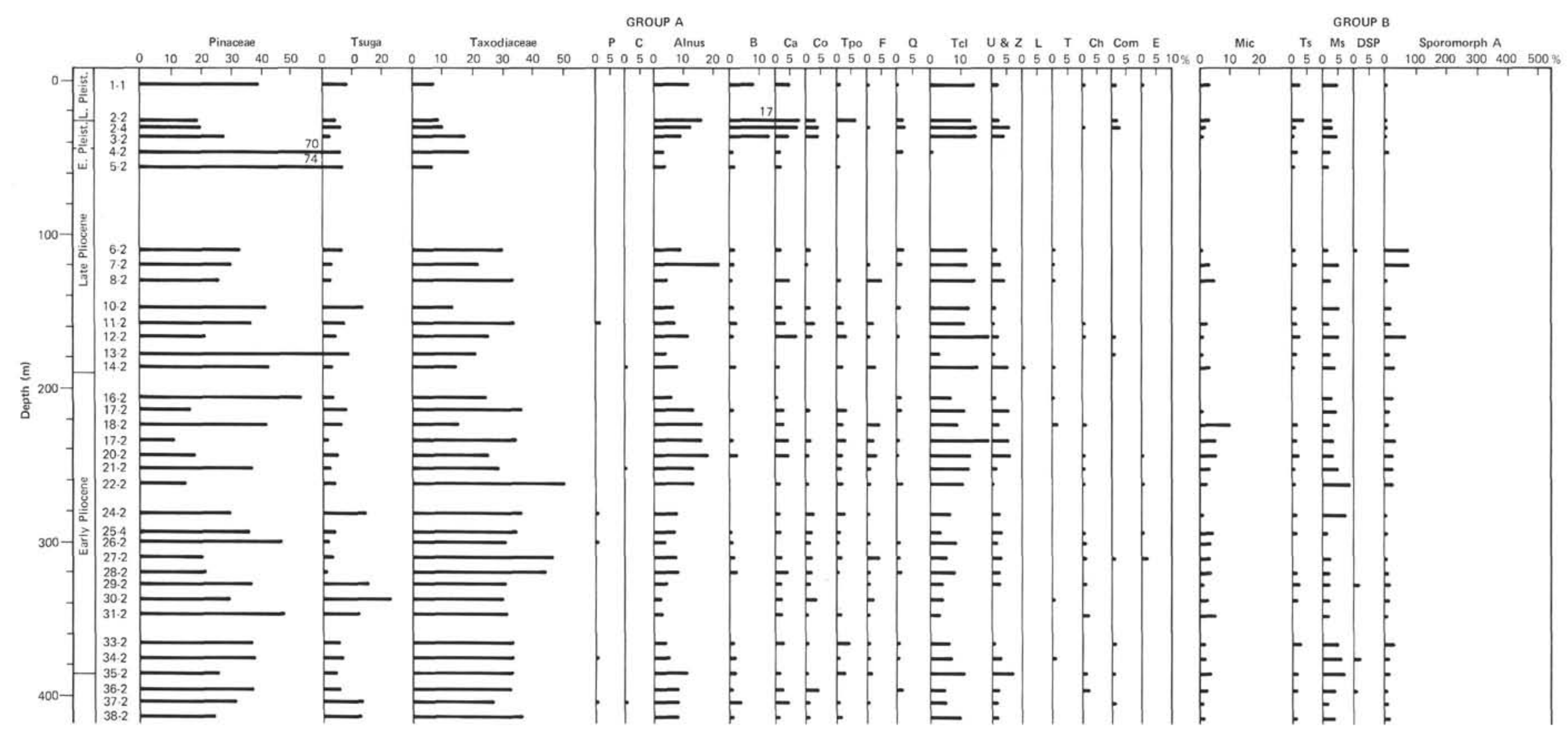




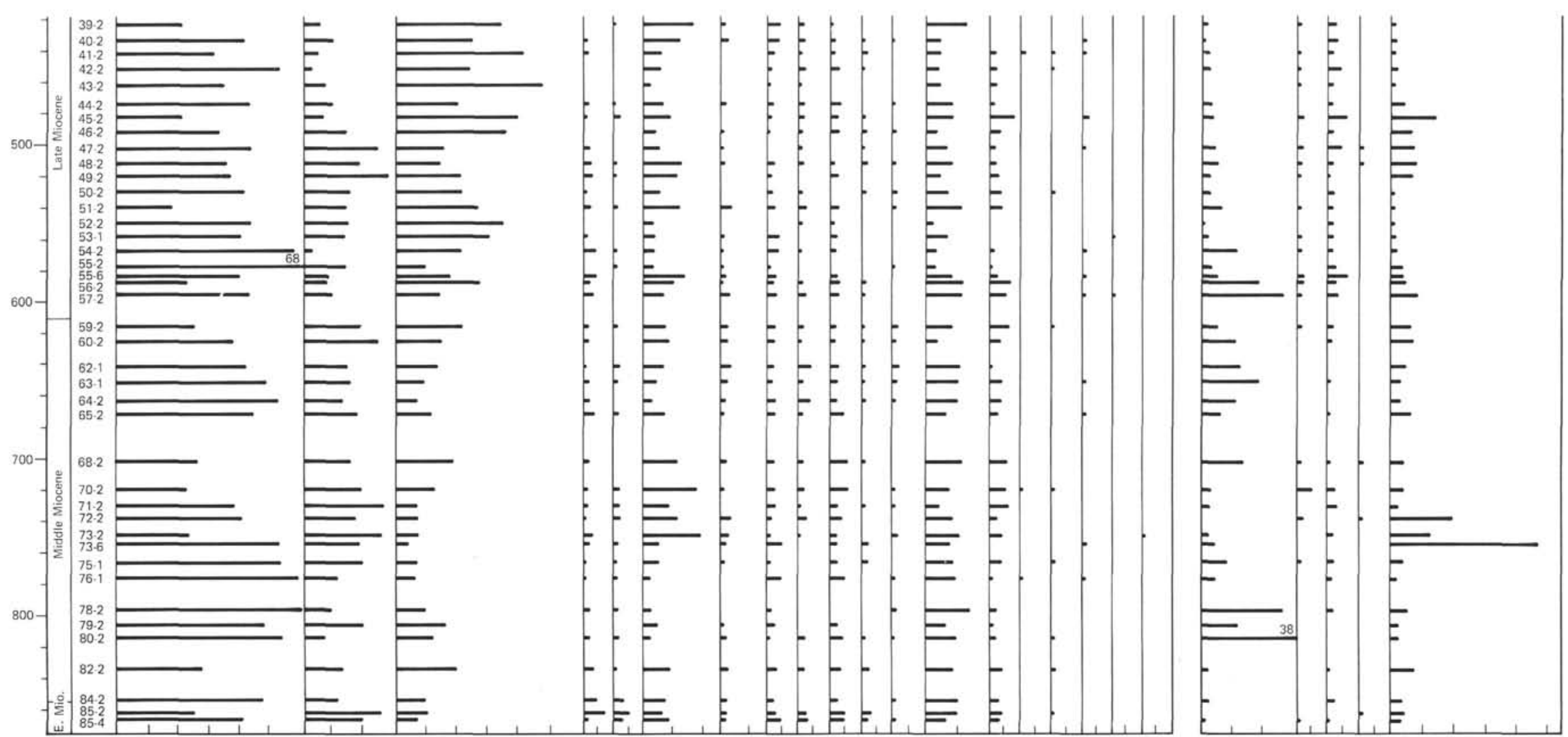

Figure 2. Pollen diagram of Hole 438 A sediments. The age assignment is based on diatoms, radiolarians, nannofossils, and foraminifers. Group A pollen types are shown as relative per cent of the total pollen assemblage (counts of 150-200 pollen grains). Group B (microplanktons, spores, and Sporomorph A) are shown as percentage abundance relative to pollen; thus percentage can exceed 100. Key: P: Pterocarya. C: Carya. B: Betula. Ca: Carpinus. Co: Corylus. Tpo: Triporate pollen, genus indeterminable. F: Fagus. Q: Quercus. Tcl: Tricolpate pollen, genus indeterminable. U \& Z: Ulmus and Zelkova. L: Liquidambar. T: Tilia. Ch: Chenopodiaceae. Com: Compositae. E: Ericeae. Microplanktons: mainly dinoflagellata and acritarchs. Ts: Trilete spores. Ms: Monolete spores. DSP: Spores and pollens clearly judged to derive from Cretaceous rocks, based on their characteristic shapes. Sporomorph A: Spherical, less than $10 \mu \mathrm{m}$ in diameter, surface smooth, biological affinity unknown, not found in terrestrial sediments. 